\title{
Regulation of advance directives in Italy: further considerations
}

Nereo Zamperetti, Rinaldo Bellomo, Fabio Zappin, Claudio Ronco, Pasquale Piccinni

Authors Address:

Nereo Zamperetti, MD ( $\square$ )

Department of Anesthesia and Intensive Care Medicine

San Bortolo Hospital, Via Rodolfi, 37

36100 Vicenza - Italy

tel.: 0039-0444-753508 (secr.), 0039-0444-753862 (ICU)

fax: 0039-0444-753508

e-mail: nereo.zamperetti@ulssvicenza.it

Rinaldo Bellomo, MD

Department of Intensive Care,

Austin \& Repatriation Medical Center,

Heidelberg, Victoria - Australia

Fabio Zappin

Service for Quality, Safety and Accreditation

San Bortolo Hospital, Vicenza - Italy

Claudio Ronco MD

Department of Nephrology, Dialysis and Transplantation, International Renal Research Institute

San Bortolo Hospital, Vicenza - Italy

Pasquale Piccinni

Department of Anesthesia and Intensive Care Medicine

San Bortolo Hospital, Vicenza - Italy

No financial funds, including departmental or institutional funding, supported the preparation of this paper.

(word count: 698) 


\section{Dear Editor,}

we read the paper of Gristina and coll. with interest (1) and would like to add some considerations.

A first concern relates to the title of the proposed bill, "Provisions on the therapeutic alliance, informed consent and advanced declaration of treatment", which suggests an attempt to regulate all the complex issues surrounding end-of-life care. Yet, the issue is then tackled by means of a reductionistic approach. First, most of the problems of end-oflife care are reduced to the care of patients in vegetative state. Then, such care is reduced to the possibility of forgoing artificial nutrition and hydration (AHN). This is probably due to the fact that the bill was written on the wake of the controversy that followed the death of Eluana Englaro. As such, it seeks to specifically regulate the possibility of withdrawing ANH in vegetative patients. The result is that the bill is quite inadequate in regulating endof-life care in patients affected by other (much more frequent) conditions, such as cancer, COPD or cardiac failure. More importantly, it represents an example of a state seeking to impose a specific moral view on every citizen and deciding how they ought to live their private lives, including their terminal phase. In this sense, the Italian College of Physicians specifically requested that Parliament should respect the relationship between the care provider and the patient, and proposed the adoption of 'diritto mite' (a soft legislation)" (2).

A second concern is that - in an attempt to balance different values grounded in the Italian Constitution (life, health, dignity, self-determination, individual freedom) - the proposed bill grants a strong privilege to life, intended as physical survival, over and above all other values. Within this framework, the patient's right to care turns into a clinician's duty to treat.

A further point relates to the roles of advanced directives (AD) and of the clinician. The proposed bill assigns only a weak indicative value to the patient's will, which would then be evaluated by the clinician under no legal obligation to respect it. Much public opinion in Italy believes that a clinician's obligation is to fulfil the patient's wishes. We note, however, that making AD mandatory would be in contrast with the Oviedo Convention (3) and the Italian Medical Code of Ethics, which strongly support AD but maintain such AD should be "taken into consideration" and not mechanically fulfilled.

We believe a more effective approach to this issue can be achieved by recognising that situations are different, and, accordingly, AD should also be different. Some young, healthy people may want to define their level of care in case of a possible but unlikely clinical situation which they are not able to precisely understand and specify. This type of $A D$ could be defined as eventuality $\boldsymbol{A D}$ and would represent a generic patient preference, which although important, needs to be interpreted by the family and the clinician before being applied (usually many years after its formulation). In these situations, the evaluation of the reliability of the expressed will is a necessary step to ensure the very respect of the patient's values and autonomy: it is the overall intention of the patient's will which must be fulfilled, not its mere literal expression.

A different form of $A D$ might apply to patients affected by chronic and/or degenerative diseases. These patients know and understand their condition very well because they live with it every day. Moreover, the progression of their illness is well understood and well- 
defined. These AD could be defined as expectation $\boldsymbol{A D}$. They would represent the patient's specific will, which requires little interpretation by the family and the clinician and needs simply be known, shared and respected.

Even more important, we should ensure the decriminalization of the clinician's action when she/he respects the patient's will. The law should reassure the physician that, should she/he act in accordance with the patient's will, she/he will not be prosecuted. The proposed bill assigns the clinician the responsibility to decide but does not provide such reassurance (on the contrary, it stresses the overwhelming importance of physical survival over health, dignity, self-determination and individual freedom); in this sense, it risks forcing clinicians to deliver unwanted overtreatment to terminally ill patients.

\section{References}

1. Gristina GR, Martin E, Ranieri VM (2012) Regulation of advance directives in Italy: a bad law in the making. Intensive Care Med DOI 10.1007/s00134-012-2656-3.

2. Federazione Nazionale degli Ordini dei Medici Chirurghi e degli Odontoiatri (2009). Documento del Consiglio Nazionale della FNOMCeO sulle D.A.T. http://www.omceoudine.it/news/195. Accessed 25 Aug. 2012

3. Council of Europe convention for the protection of human rights and dignity of the human being with regard to the application of biology and medicine: convention on human rights and biomedicine. In: http://conventions.coe.int/Treaty/en/Treaties/Html/164.htm. 